\title{
Endocytosis of Magnetic Microspheres Into Cells
}

\author{
Won Hyuk Suh*1 ${ }^{1}$, Ah Ram Jang**, Catherine S. Lee*2, Yoo-Hun Suh**, Kenneth S. Suslick*1 \\ *1 School of Chemical Sciences, University of Illinois at Urbana-Champaign, 600 S. Mathews Ave., \\ Urbana, IL $61821, *^{2}$ Dept. of MatSE, University of Illinois at Urbana-Champaign \\ ** Department of Pharmacology, College of Medicine, Neuroscience Research Institute, MRC, \\ National Creative Research Initiative Center for Alzheimer's Dementia, Seoul National University, \\ 28 Yongon-dong, Chongno-gu, Seoul 110-799, South Korea
}

\begin{abstract}
We have developed a facile and simple method to synthesize magnetic microspheres and delivery of them into living cells. Visualization of endocytosis was done via optical and electron microscopy. Magnetic microspheres were produced using an ultrasonic spray pyrolysis (USP) technique and were analyzed using XRD, SEM, (S)TEM, and SQUID. Cellular experiments were conducted using two mammalian cell lines. Key in the visualization process is the use of PDMS (poly(dimethylsiloxane) as the substrate of cell growth.
\end{abstract}

\section{Synthesis, Characterization, and Endocytosis of Microspheres}

USP has been employed to create multitude of materials from fluorescent nanoparticles to porous microspheres both from our group [1] and others [2]. Microphotograph of the ultrasonic fountain is given in Fig. 1 and the fine mist droplets created are approximately 5-6 micron in size. The precursor used for this study is comprised of $\mathrm{Ti}(\mathrm{IV})$ bis(ammonium lactato) dihydroxide and $\mathrm{Co}(\mathrm{OAc})_{2}(5: 1$ ratio, $0.6 \mathrm{M}, 1 \mathrm{~L} / \mathrm{min}$ Air, $850{ }^{\circ} \mathrm{C}$ ). USP afforded the oxide and heat treatment of the oxide microspheres under $5 \%$ hydrogen $\left(95 \%\right.$ nitrogen) gas at $600{ }^{\circ} \mathrm{C}$ afforded magnetic microspheres. SEM and TEM analysis (Fig. 2) shows the appearance of nanoparticle cobalt on the surface of the microspheres. XRD (Fig. 3) analysis revealed that prior to heat treatment the oxide microspheres were a composite of cobalt oxide $\left(\mathrm{Co}_{3} \mathrm{O}_{4}\right)$, cobalt titanate $\left(\mathrm{CoTiO}_{3}\right)$, rutile and anatase titania (majority). After reduction at $600{ }^{\circ} \mathrm{C}$, however, $\mathrm{Co}_{3} \mathrm{O}_{4}$ disappeared and cobalt (Co metal) peaks appeared. Magnetic characterization (SQUID, Fig. 4) clearly shows the presence of ferromagnetic cobalt.

For cell experiments, HEK293 (human kidney) and SHSY5Y (human neuroblastoma) cells were incubated with magnetic microspheres for a day. Optical/confocal microscope images clearly shows the endocytosized microspheres inside the cytosol. The particles did not penetrate into the nucleus and that was confirmed upon SEM of the cells grown on PDMS (Fig. 5, 6). First, PDMS was cured inside 96 or 24 well plates. Second, cells were incubated with magnetic microspheres. Third, optical microscope images were taken with the media present since PDMS is transparent. Fourth, SEM of cells was done after the removal of cell media and the dehydration of each PDMS substrate.

\section{References}

[1] W. H. Suh and K. S. Suslick, J. Am. Chem. Soc. 127 (2005), 12007.

[2] K. Okuyama and I. W. Lenggoro, Chem. Eng. Sci. 58 (2003), 537. 
[3] We thank NSF (CHE-03-15494 to KSS) and the CRI and BK21 (to YHS) for funding. Analysis was carried out at the SQUID facility and the Center for Microanalysis of Materials at the UIUC Frederick Seitz Materials Research laboratory supported by the DOE (DEFG02-91-ER45439).
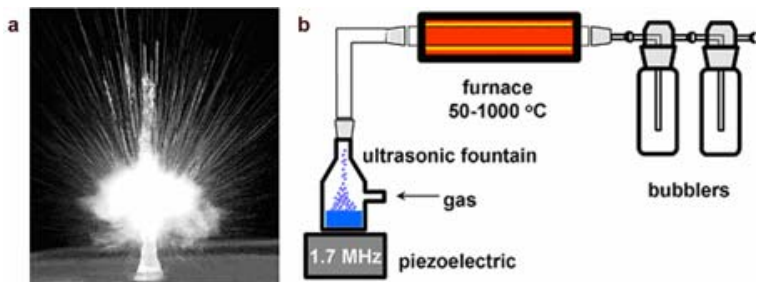

Fig. 1. Ultrasonic Spray Pyrolysis. (a) Ultrasonic fountain. (b) USP setup.
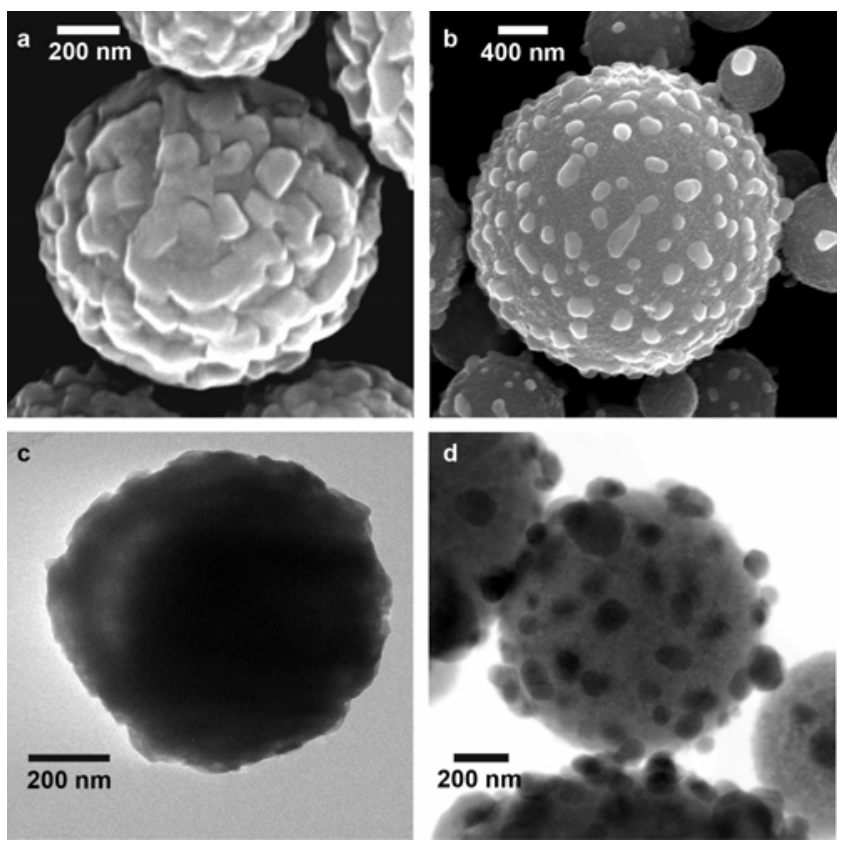

Fig. 2. Electron Micrographs. (a,b) SEM of microspheres before (left) and after (right) heat treatment. (c,d) TEM of a, b.

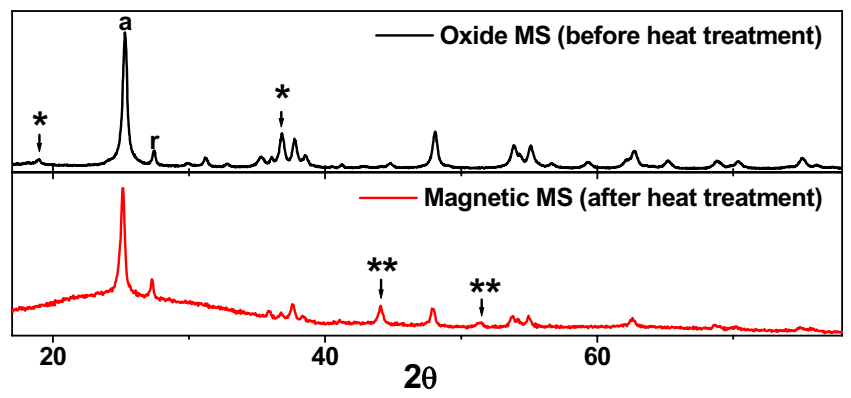

Fig. 3. XRD patterns for (a) before heat treatment and (b) after heat treatment. $\left(*=\mathrm{Co}_{3} \mathrm{O}_{4}, * *=\mathrm{Co}\right.$ metal, $\mathrm{a}=$ anatase, $\mathrm{r}=$ rutile)

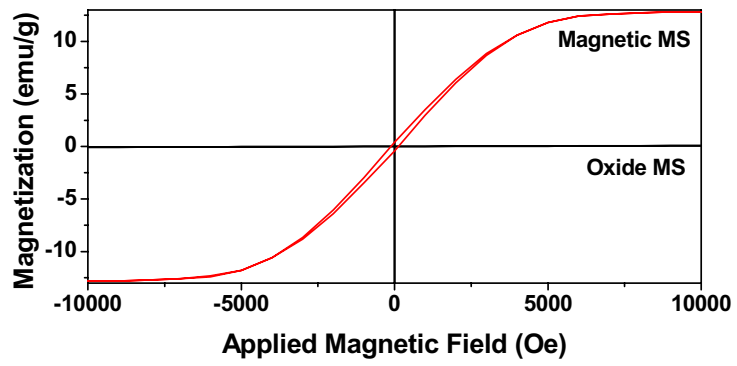

Fig. 4. Magnetic responses (298K) for before (paramagnetic) and after (ferromagnetic) heat treatment.

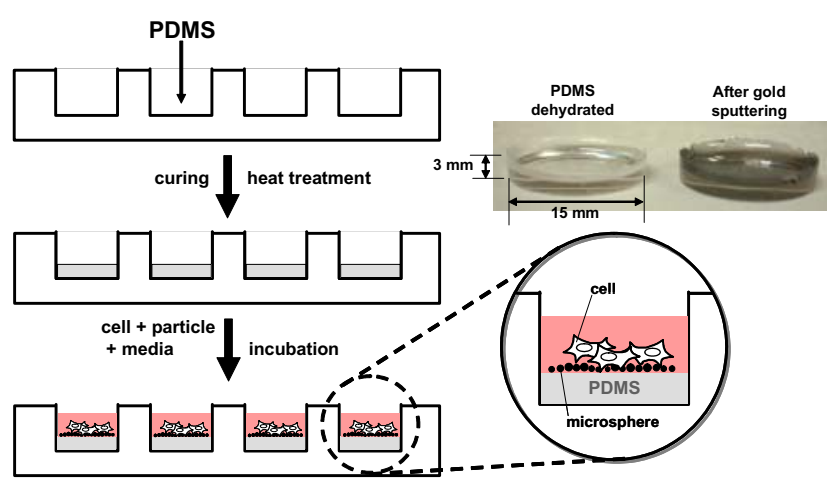

Fig. 5. Schematic of PDMS stages inside incubator well plates.
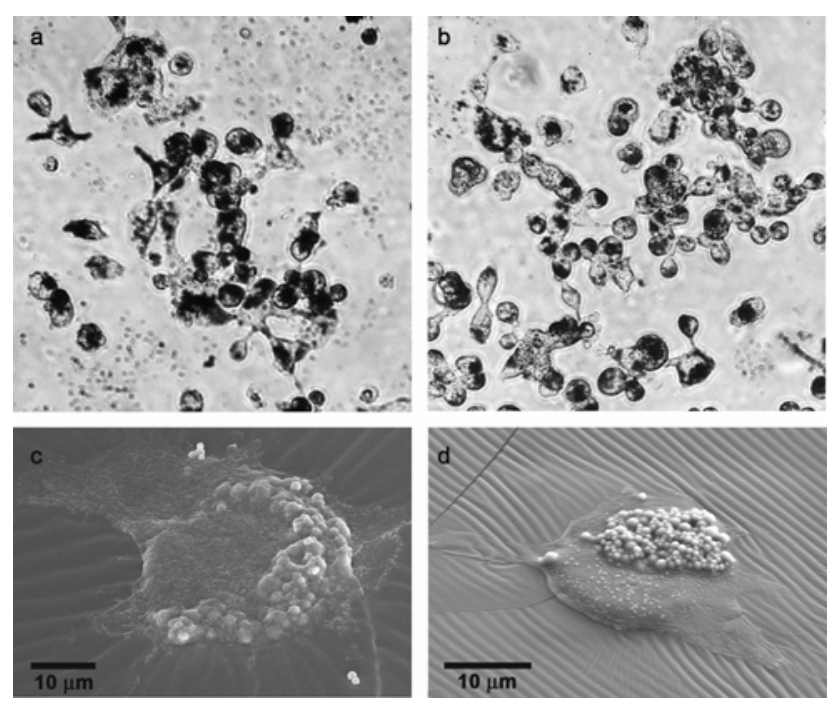

Fig. 6. Microscope images. $(\mathrm{a}, \mathrm{c})$ optical and SEM of SHSY5Y cells. (b,d) optical and SEM of HEK293 cells. 